\title{
A competency-based approach to nurses' continuing education for clinical reasoning and leadership through reflective practice in a care situation
}

\author{
Johanne Goudreau, RN, Ph.D. ${ }^{1-2}$, Jacinthe Pepin, RN, Ph.D. ${ }^{1-2}$, Caroline Larue, RN, Ph.D. ${ }^{1-2}$, \\ Sylvie Dubois, RN, Ph.D. ${ }^{1-3}$, Renée Descôteaux, RN, M.Sc. ${ }^{4}$, Patrick Lavoie, RN, Ph.D. \\ candidate $^{1-2} \&$ Katia Dumont, M.A. ${ }^{1}$ \\ ${ }^{1}$ Faculty of Nursing, Université de Montréal, C.P. 6128 succ. Centre-Ville, Montreal, QC, Canada, H3C 3J7 \\ ${ }^{2}$ Center for Innovation in Nursing Education (CIFI), Faculty of Nursing, Université de Montréal, C.P. 6128 succ. \\ Centre-Ville, Montreal, QC, Canada, H3C 3J7 \\ 3 , Centre hospitalier de l'Université de Montréal, Pavillon S, 850 rue Saint-Denis, porte S06-258, Montreal, QC, \\ Canada, H2X 0A9 \\ ${ }^{4}$ Centre Hospitalier Universitaire Sainte-Justine, 3175 Chemin de la Côte-Sainte-Catherine, Montreal, QC, Canada, \\ H3T 1C5
}

Corresponding author: Johanne Goudreau, johanne.goudreau@umontreal.ca,

1 (514) 343-6178, C.P. 6128 succ. Centre-Ville, Montreal, QC, Canada, H3C 3J7

Coauthors: jacinthe.pepin@umontreal.ca, caroline.larue @umontreal.ca, sylvie.dubois.chum@ssss.gouv.qc.ca, renee.descoteau.hsj@ssss.gouv.qc.ca, patrick.lavoie.1@umontreal.ca, katia.dumont@cqld.ca

Acknowledgement: The Canadian Foundation for Healthcare Improvement funded this study. 


\begin{abstract}
Newly graduated nurses need to demonstrate high levels of competencies when they enter the workplace. A competency-based approach to their education is recommended to ensure patients' needs are met. A continuing education intervention consistent with the competency-based approach to education was designed and implemented in eight care units in two teaching hospitals. It consists of a series of 30-minute reflective practice groups on clinical events that newly graduated nurses encountered in their practice. It was evaluated using a descriptive longitudinal evaluative research design, combining individual and group interviews with stakeholders, the analysis of facilitators' journal entries, and a research assistant' field notes. The results suggest that issues associated with the implementation of the continuing education intervention revolved around leadership for managers, flexibility for nursing staff, and role shifting for the facilitators. Newly graduated nurses who participated in the study noted that the reflective practice sessions contributed to the development of both clinical reasoning and leadership. Nursing managers stated the advantages of the intervention on nurses' professional development and for the quality and safety of care. Following the end of the study, participants from two units managed to pursue the activity during their work time.
\end{abstract}

Keywords: continuing education, competency-based approach to education, reflective practice, newly graduated nurses.

\title{
INTRODUCTION
}

In the actual context of care, nurses are expected to provide patient-centered and evidencebased care and to lead quality improvement efforts, while influencing healthcare organizations (Cronenwett et al., 2007; Institute of Medicine, 2011). This means they need to demonstrate high levels of competencies such as clinical reasoning and clinical leadership in their clinical practice (Bartels and Bednash, 2005; Cronenwett et al., 2007). However, static, fragmented and 
sometimes outdated education curricula are said to create discrepancies between patients' needs and health professionals' competencies, and so reform towards competency-based approaches to education has been suggested (Frenk et al., 2010). These approaches are based upon a longitudinal view of the development of competencies, from pre-registration programs to continuing education (Cronenwett et al., 2007; Institute of Medicine, 2011).

In this spirit, a fourfold research program was conducted to develop and validate an integrated competency-based approach to nurses' education from academia to practice (Authors, 2011, 2013, 2014). The purpose of this paper is to report the results of this program's fourth study. Building on the results from the three previous studies, a continuing education intervention (CEI) was elaborated and implemented in two Canadian public tertiary teaching hospitals in an urban setting. The CEI consisted of a series of 30-minutes reflective practice sessions during which four to five nurses from one unit were invited to discuss clinical events experienced in their daily practice. An experienced nurse from the unit facilitated the sessions. This paper adds to the knowledge regarding how the competency-based approach to education can guide efforts in continuing education.

\section{BACKGROUND}

\section{Framework}

The competency-based approach to education that is referred to in this research program rests on theoretical underpinnings that have been described in a previous article (Authors, 2009). In this context, a competency is defined as a "complex knowing of how to act based on the mobilization and combination of a variety of internal and external resources within a family of situations" (Tardif, 2006, p. 22). It is conceptualized as a situated knowledge that will develop throughout a learner's life. Because of its developmental nature, it is necessary to understand the steps through which a competency progresses in order to plan teaching-learning activities. A 
cognitive learning model is an empirically-based description of the steps of a competency's development (National Research Council, 2001). It consists of an illustration of how a competency develops, from the very beginning of training, through expertise, with the required critical learning points characterizing each step.

The competency-based approach to education relies on teaching-learning strategies that place the learner in an active position and make him responsible for his learning (Lasnier, 2000). In a manner similar to situated learning (Anderson et al., 1996), knowledge is built through exercises grounded in the context it is to be used in. These exercises allow the learner to mobilize both his internal resources (different types of knowledge) and external resources (external information sources) when solving problems similar to those that are to be faced in real life.

\section{The research program}

The aim of the first two studies of the research program was to develop cognitive learning models of two nursing competencies: clinical reasoning (authors, 2014) and clinical leadership (authors, 2011). An alarming finding of these studies was that when newly graduated nurses (NGN) enter the workplace, they tend to stop the development of their competencies to embrace and fade into working routines. This seems to be related to the transition shock experienced by NGN when they enter the context of professional practice (Duchscher, 2009). This period is described as one of the most stressful and challenging in a nurse's career (Morrow, 2009).

Therefore, the research program's third study (authors, 2013) aimed at understanding the NGN' learning processes during their first 24 months of practice and the activities organized in the work place to support their professional development. From the results, it appears that NGN prefer to learn from clinical experiences and role models. Paradoxically, nursing managers believed that nurses were limited in their capacity to learn from lived clinical experiences due to the absence of a period of reflection during their working time. They also stated that a strong 
leadership from managers on the wards is necessary to support the development of NGN' competencies.

Based on these results, a CEI dedicated to reflective practice on everyday clinical situations was to be held on different units in our associated health centers. The CEI would aim at supporting the development of NGN' clinical reasoning and clinical leadership. The use of reflective practice is consistent with a competency-based approach to education.

\section{Studies of similar interventions}

Reflective practice as a strategy for continuing education is well documented in the nursing literature. Through database search, we retrieved sixteen articles that used such a strategy with registered nurses in the workplace. These papers documented reflective practice as a CEI to deal with specific issues such as care for hospitalized elderly patients (Dube and Ducharme, 2014), critical thinking skills (Forneris and Peden-McAlpine, 2007), therapeutic communication (Kemp et al., 2009), use of coercion (Olofsson, 2005), cardiopulmonary resuscitation (Page and Meerabeau, 2000), or family care (Peden-McAlpine et al., 2005). These interventions consist of group meetings held specifically to discuss daily clinical situations. All but one are conducted outside work time, with duration varying from one hour (Dawber, 2013b; Lakeman and Glasgow, 2009; McVey and Jones, 2012; Taylor, 2001) to a whole day (Kemp et al., 2009; Stanley and Simmons, 2011). One study described a 45-minutes reflective practice intervention taking place during nurses' shift (Dawber, 2013a). All interventions implied a prolonged commitment to the group, from six weeks (Kemp et al., 2009) to three years (Dawber, 2013b), with most lasting between six months and a year.

These interventions encompass diverse approaches to reflective practice, drawing on theoretical work of experiential learning (Kolb, 1984), reflection (Argyris and Schön, 1974; Atkins and Murphy, 1993; Boud et al., 1985; Gibbs, 1988; Johns, 1995; Schön, 1983, 1987), or 
the critical incident technique (Brookfield, 1990). Participants are invited to describe and analyse clinical situations in order to illuminate proper nursing actions if similar situations were to occur again. Furthermore, since these activities are group based, there is always a facilitator trained to lead the group. The group interactions are seen as opportunities for participating nurses to share a variety of insights and to develop as professionals. In four of these activities, participants were invited to write a journal between meetings (Bailey and Graham, 2007; Dube and Ducharme, 2014; Forneris and Peden-McAlpine, 2007; Taylor, 2001) and, in three activities, there were some didactic contents (Dube and Ducharme, 2014; Kemp et al., 2009; Peden-McAlpine et al., 2005).

Methodologically, qualitative methods prevail. In four studies, action research methods were used in which participants were engaged in the cyclical planning and conduction of the research (Alleyne and Jumaa, 2007; Dube and Ducharme, 2014; Lakeman and Glasgow, 2009; Taylor, 2001). Another was a phenomenological study aimed at exploring participants' experience of reflective practice (Peden-McAlpine et al., 2005). The two quantitative approaches used mixed methods designs, where quantitative data were collected to assess participants' perceptions of the intervention and its effect (Dawber, 2013b) or to appraise the intervention's effects on participants' knowledge and attitudes (Dube and Ducharme, 2014).

In these studies, participants thought that the CEIs contributed to their professional development, mostly because they perceived an improvement in their self-confidence when preparing for future similar situations (Alleyne and Jumaa, 2007; Bailey and Graham, 2007; Dawber, 2013b; Kemp et al., 2009; McVey and Jones, 2012; Olofsson, 2005; Peden-McAlpine et al., 2005; Stanley and Simmons, 2011). Participants valued the opportunity to reflect on their practice, even though they said they did not fully understand the reflective practice process and that time and perseverance were mandatory (Bailey and Graham, 2007; Kenny and Allenby, 
2013). Nevertheless, there seems to be a process by which participants gradually became more comfortable and intentional in their use of reflective practice (Forneris and Peden-McAlpine, 2007; Taylor, 2001). Participants felt safe and confident sharing clinical issues within their group, where they experienced trust and respect for colleagues (Dawber, 2013b; McVey and Jones, 2012; Olofsson, 2005). Moreover, the CEIs were perceived as opportunities to work through feelings and obtain support from colleagues (Dawber, 2013b; Lakeman and Glasgow, 2009; McVey and Jones, 2012; Olofsson, 2005; Page and Meerabeau, 2000). Evidence from one quantitative study suggested that such an approach could contribute to participants' knowledge and attitudes (Dube and Ducharme, 2014). In two studies, participants acknowledged that a clear goal was essential to ensure that the discussions were actually learning opportunities as well as a source of psychological support (Kenny and Allenby, 2013; Page and Meerabeau, 2000).

Issues of time were also reported (Kenny and Allenby, 2013; Lakeman and Glasgow, 2009; Olofsson, 2005; Stanley and Simmons, 2011). They were related to prioritizing reflective practice over other tasks on the units and making the activity durable over time (Bailey and Graham, 2007). However, few papers described the challenges associated with the CEIs' implementation and fewer were conducted across multiple sites. It appears that those CEIs ceased at the end of the studies. None relied on a competency-based approach to education as their framework.

\section{RESEARCH DESIGN}

Inspired by Patton's utilization-focused evaluation (2006), this study used a descriptive longitudinal evaluative design to describe 1) the implementation of the CEI; 2) NGN' perceptions of their clinical reasoning and clinical leadership development following participation in the CEI; and 3) nursing managers' perceptions of the utility, acceptability and feasibility of the CEI. This was meant to get a stakeholders' perspective on the implementation of the CEI.

\section{Settings and participants}


The CEI was implemented in eight care units in two tertiary teaching hospitals and was offered to day, evening and night shifts. Chief executives of nursing and two clinical nurse specialists from each hospital were included as co-researchers and had participated in the three previous studies since the very beginning of their design phase. The first hospital is a 450-bed facility specialized in paediatric care. The other is a network of three hospitals with a total capacity of 1001 beds offering a wide range of specialties. Inclusion in the study was on a voluntary basis, after chief nursing officers explained the study to the units' head nurses. Ethical approval for this study was obtained from both hospitals' ethical review board.

Three convenience samples were drawn from the eight units. The first comprised nurses with managing roles (head nurses, clinical nurse specialists) $(n=12)$. The second consisted of the nurses $(n=18)$ who facilitated the 30-minute CEI sessions. NGN ( $n=55)$ who were recruited to attend those sessions made up the third sample. Characteristics of participants of the second and third samples are presented in Table 1.

\section{Intervention}

Only the NGN were invited to participate in the study, but all the other nurses could attend the CEI's sessions. As such, groups of four to five nurses with various levels of expertise attended. NGN participating in the study were asked to join at least 10 sessions over a period of 20 weeks.

During each session, at least one NGN reported on a recent situation that was challenging for her. The situation could be clinical or of any other type, for example related to an issue of collaboration. The goal of the CEI session was to understand the situation in order to widen and deepen all participants' perspectives. The discussion covered the comprehension of the situation and of nursing interventions if applicable, in order to nurture future practices. An approach inspired by a post-simulation debriefing model (authors, 2013) that was adapted from a guide for reflective journaling (Nielsen et al., 2007) was used to structure the sessions (Figure 1). 
At the beginning of a session, the facilitator invited the participating NGN to share potential situations to discuss with the group. Once the participants reached consensus on a particular situation, the facilitator asked the nurse who related it to describe it in greater detail, to specify what she thought were significant facts, and to express her feelings about it. Then, other participants could ask any clarifying questions to get a more complete and detailed picture. After all the clarifications were made, the participants were asked to draw links across the data and to identify other data that would have been useful to get. The situation could also be compared to participants' previous experiences to see if parallels could be drawn. Through this process, the participants were asked to formulate a hypothesis that could explain the collected data. All hypotheses were critically appraised to see if they fit the data, until the group selected one as the most plausible. Only then could the participants suggest hypothetical interventions. These hypotheses were also critically examined, and, even though difficult because of the time constraints, the participants were also invited to refer to scientific literature to identify evidencebased interventions. At the end of the session, the participants were invited to describe what they had learned during the session and to set an observable and measurable objective to improve their practice.

Eighteen experienced nurses were trained to facilitate the sessions. The training pertained to small group facilitation (Saint-Arnaud, 2008) and the reflective approach. Also, since the facilitators-to-be were asked to organize the sessions in their units, there were discussions about how to plan this kind of activity. When the CEI started, each facilitator was coached by a clinical nurse specialist or a member of the research team and received feedback for continuous improvement in the facilitating process.

\section{Data collection and analysis}


Data collection techniques are described in Table 2. Journals and group and individual interview audiotapes were transcribed in QDA Miner@ by a research assistant. This data was analysed by a second research assistant with a thematic approach (Paillé and Mucchielli, 2012), specifically, the transcripts were coded in an inductive manner to identify the themes in the participants' accounts. Once a first list of themes was determined, the first research assistant counter-coded a $15 \%$ sample of the data. The list of themes was refined and reorganized until a 90\% inter-rater agreement was reached for the coding procedure.

The first research assistant's field notes were also analyzed through reading and rereading to search for significant sections, and by drafting a summary. Once all the data was reduced, a questioning approach was used for analysis (Paillé and Mucchielli, 2012). Namely, an analysis canvas was elaborated, looking for acceptability, utility and feasibility results in the data that was collected. The questions allowed for the exploration of the themes and the summary of the field notes. The questions evolved according to new issues and themes that emerged during this process.

\section{FINDINGS}

First, issues associated with the implementation of the CEI appeared to revolve around leadership for managers, flexibility for nursing staff, and role shifting for the facilitators. Second, the participating NGN revealed that the CEI contributed to the development of both clinical reasoning and leadership. Third, the nursing managers shared the advantages of the CEI for the professional development of NGN as well as for the quality and safety of care.

\section{Implementation of the CEI}

The first issue in the implementation process was the unexpected need for leadership from nursing management. Since the facilitators-to-be kept postponing the first session because they did not feel ready for group facilitation and were not comfortable with the reflective approach, 
chief nursing officers and clinical nurse specialists had to get involved in the basic planning of the CEI. Conversely, they planned the sessions according to the nursing staff schedule, so as to maximize NGN' attendance while also soliciting more experienced nursing colleagues.

The timing of the sessions was the second crucial issue and it varied from unit to unit, which meant nursing staff had to be flexible with the CEI. On some units, it was possible to hold the CEI during work time. In those cases, no specific time was scheduled; the facilitator would choose the proper moment according to the unit's workflow. These sessions generally took place at the nurses' station. As such, participants reported they were frequently interrupted and were unable to concentrate properly on what was going on in the sessions. For this reason, nurses on other units felt it was not possible to hold the sessions during work time. On those units, nursing managers organized joint sessions for staff from the day and evening shifts, so nurses would stay later or come in earlier. These sessions were held in the break room and the nurses were not disturbed. As for nurses on the night shift, they planned the sessions during the work shift with minimal difficulty, using one third of their break. As planned, sessions lasted approximately 30 minutes. Their frequency varied: some units held one or two sessions a week, while others preferred biweekly schedules.

Another issue of flexibility concerned the matters that were brought up for discussion. A great diversity of events was addressed; the most frequent being clinical, such as care for acutely unwell patients. Participants also discussed care organization, intercultural care, and the influence of their personal values on patient care. NGN raised most of the events for discussion, except when the sessions were close to one another. In those cases, the facilitators had to propose topics for discussion, which led to the idea of developing a bank of situations for reflection, which could be shared with the participating units. 
The facilitators added that the nature of the events had a profound impact on the climate of the session. For example, when a subject with a strong emotional content was addressed, participants were likely to express a feeling of discomfort. Facilitators felt this was a difficult situation to manage.

Throughout the session, the facilitators experienced a shift in their perception of their role, which was clearly acknowledged in their journals. At first, they perceived themselves as knowledge holders. Conversely, they tended to formulate close-ended questions or to suggest answers to the participants during the reflection. Thanks to the feedback from the coaches and their self-assessment through journaling, they gradually became aware of the necessity to adjust their behaviour so that they would act more as facilitators of the reflective process. In their journals, the facilitators explained that they progressively developed strategies to effectively manage time and participation during the sessions, such as soliciting participants who were less active or asking talkative participants to listen to other colleagues' insights.

\section{NGN' perceptions of the development of their competencies}

NGN felt that the CEI was a valuable learning opportunity that contributed to development of their competencies. With regard to clinical reasoning, according to NGN' individual interviews, the CEI helped them make more links among the data they collected from clinical events. This made them more aware of the missing data that was needed for a more thorough assessment. Thus, the CEI facilitated the development of their ability to question and gather relevant data. One quote from an interview illustrates this point:

"Instead of just going through the motions, I learned to make links and to understand what the symptoms mean, why [the patient] has them and not just say: "Well, he is in pain!” [I learned] to go deeper because I don't want to miss a thing, anything; I don't 
want the patient to experience a complication that I could have prevented just because I didn’t dig deep enough.” (NGN 270313-2's interview)

Through discussions with their colleagues during the CEI, NGN came to consider new interventions that could be integrated in their practice. Therefore, they believed they were more prepared to face similar situations in the future.

Regarding clinical leadership, NGN perceived an improvement in their confidence, which has resulted in more interventions on their part within the inter-professional team. As such, they were sharing more of their professional observations and opinions with other professionals. Since they were more aware of inter-professional resources, they tended to use these resources more actively than before. Overall, they reported that their vision of the nursing role in the actual context of care had evolved, as had their view of clinical situations, which they consider more holistically and reflectively.

All the NGN interviewed stated that they would continue to participate in the CEI after the study's end even if they asserted that a combination of work experience and the CEI had a larger impact on their development than the CEI alone. Some explained that their participation would be conditional on some incentives: the participation of expert nurses, a fixed weekly schedule, a maximum length of 30 minutes per session, and the availability of a bank of situations for reflection. Some also suggested that the session could take place outside of work.

It should be noted that participants from two units (one by hospital) have committed to pursuing the CEI after the study. To date, these groups have managed to find time during their shifts to organize CEI sessions. According to those participants, a thorough understanding of the reflective process and their trust in its benefits, the support and conviction of their unit's managers, and the facilitator's motivation encouraged their long-term adherence to the CEI. It was also noted during data analysis that facilitators from the groups where it was decided to 
pursue the CEI tended to write more detailed accounts of the sessions and clearly acknowledged the benefits gained from the CEI.

\section{Managers' perceptions}

All managers agreed on the CEI's added value. First, they were all convinced that such an educational intervention contributed to the development of the NGN' competencies and that this had an impact on patients' safety and the quality of their care. More specifically, they said that the CEI allowed NGN to widen their view on clinical situations by comparing their perceptions with those of their peers. Secondly, managers asserted that the reflection space created within the CEI constituted a space for support between NGN and more experienced nurses, and that it was an opportunity to strengthen the bonds within the teams. Furthermore, some managers said they became aware of the NGN' emotional needs during the transition to the workplace. Thirdly, the CEI's sessions were perceived as places to make nursing staff's voices heard. Managers stated that through these reflective discussions, creative solutions to issues encountered on the wards emerged. They were also a means to identify staff's learning needs and to plan educational efforts accordingly. Fourth, managers believed that the CEI could be a positive factor in attracting and retaining nursing staff on their units.

Managers discussed facilitating factors and barriers to the CEI's implementation. The participants' and the facilitators' motivation, respect and openness between colleagues, and the participation of expert nurses contributed to the success of the CEI, along with the incentive measures that were organized (remuneration of the overtime hours; continuing education credits). On the other hand, difficulties in organizing the CEI sessions, lack of commitment from participants and facilitators, and limited budgets acted as barriers to the CEI's implementation.

\section{DISCUSSION}


In this paper, we have presented the design, implementation and evaluation of a competencybased approach continuing education intervention. It consisted of a series of 30-minute reflective practice sessions. The sessions were held on-site, in the units, and newly graduated nurses were invited to share clinical events of their daily practice for discussion. The findings suggest that this type of CEI is feasible with proper leadership and support from managers as well as commitment from the nurses on the units where it is to be implemented. Furthermore, it can contribute to the development of NGN' competencies as they acquire new insights on clinical events and on the nursing role within an inter-professional team. Accordingly, the competency-based approach to education is a compelling framework for continuing education in the workplace, although it represents a clear cultural shift.

For learners, the competency-based approach to education suggests that they are at the center of their learning experiences and should use work experiences as learning opportunities. This was empirically confirmed in the third study of our research program (authors, 2013) when NGN asserted that they preferred to learn from work experiences. The CEI established a space and a systematic process for participants to be able to learn from these experiences. Moreover, the attendance of more experienced nurses created an opportunity for NGN to meet with role models, which was also a learning strategy they had pinpointed as contributing to the development of their competencies in the third study. This outcome of collegiality, trust and support between colleagues was a recurring finding in other studies of similar interventions (Dawber, 2013b; Lakeman and Glasgow, 2009; McVey and Jones, 2012; Olofsson, 2005; Page and Meerabeau, 2000).

The results of the present study show that NGN felt the CEI contributed to the development of their clinical reasoning and their clinical leadership, whether through an improvement in their self-confidence or in their understanding of and preparation for similar situations. These results 
support those of other studies where participants asserted that reflecting on their practice contributed to similar outcomes in their professional development (Alleyne and Jumaa, 2007; Bailey and Graham, 2007; Dawber, 2013b; Kemp et al., 2009; McVey and Jones, 2012; Olofsson, 2005; Peden-McAlpine et al., 2005; Stanley and Simmons, 2011). Because all NGN said they would continue to participate in such reflections and some of them did, it is safe to say that our CEI was perceived positively and that NGN believed in its contribution to the development of their competencies.

For teachers, the competency-based approach to education implies a transformation of their role, from informants to facilitators of learning. During CEI sessions, facilitators clearly experienced this shift and had to adjust their behaviour accordingly. This meant they had to learn to let go of their content agenda and focus on the learners' needs. This can be contrasted with other studies where didactic content was integrated to the reflective practice interventions (Dube and Ducharme, 2014; Kemp et al., 2009; Peden-McAlpine et al., 2005). However, it is important to stress the necessity of coaching the facilitators-to-be in their learning of this new role and its corresponding vision of teaching. In our experience, the regular feedback of coaches and the facilitators' reflective journaling was useful in facilitating this transition.

The most important element of this cultural change certainly resides in the managers' relationship with continuing education. Because of its orientation towards situated learning that is based on the learners' experiences, the competency-based approach invites them to let go of rigid continuing education curricula centered on contents. Continuing education interventions such as the ones presented in this article adopt a more flexible approach to continuing education where content cannot be completely decided in advance. This entails that managers must be open to new ways of increasing professional development for their staff that aren't as static as traditional lectures or demonstrations, for instance. This is especially important since our results have shown 
that managers' support is essential for the success of the CEI's implementation. Thus, even though managers believe that nurses reflecting on their work experiences can contribute to the development of their competencies and, eventually, to the quality and safety of patient care, nurses also need to take charge of their own professional development, and suggest or initiate new methods of achieving this.

The possibility of including this intervention during nurses' work time is one of this study's most interesting findings. As explained before, most studies of similar interventions described reflective practice held outside work time, with a duration of one hour to a whole day (Dawber, 2013b; Kemp et al., 2009; Lakeman and Glasgow, 2009; McVey and Jones, 2012; Stanley and Simmons, 2011; Taylor, 2001). Even if this was not the case for most, some of this study's participants managed to find time during their shift to organize and attend the CEI. These on-shift sessions took place as regularly as the ones on units that planned them outside work time. This appeared as one of the factors that contributed to the CEI's sustainability on two on the eight units, along with understanding of the reflective process and its purposes, the support of units' managers, and facilitators' motivation.

However, participants were sometimes disturbed by demands from the unit, which was also reported in the only other study reporting on a 45-minute on-shift reflection (Dawber, 2013a). Nevertheless, participants still managed to benefit from those sessions as much as the participants from other wards. We recognize that staff from these units had to be resourceful when organizing these sessions, but they demonstrated that it is possible to use part of nurses' work time for continuing education. Given the scarcity of nursing resources, it has become difficult to release nursing staff from patients' bedside to attend continuing education, which has resulted in increased pressure on the nursing workforce to attend such activities outside of their working hours. Our results show that a CEI with reflective practice sessions is a potential avenue for 
future effort in continuing education that can be implemented with human and monetary resources already available on the units. Furthermore, thanks to its regular schedule, it can respond to nursing staff's evolving learning needs in a way that is coherent with their learning preferences.

However, our results are limited to the stakeholders' perceptions of the intervention and of its impact. These results and the absence of a control group make it difficult to draw conclusions on the actual influence the CEI has on the newly graduated nurses' competencies. Moreover, the means available to measure the development of competencies and that can realistically be used on a relatively large sample over a long period of time are limited. Therefore, further research is needed to develop such instruments. A research project where the CEI would be implemented in multiple sites with control groups is desirable to further document its implementation and to get a better view of its effect on nurses' competencies.

\section{CONCLUSION}

We designed, implemented and evaluated a continuing education intervention, which consists of a series of 30-minute reflections on clinical events in newly graduated nurses' practice. Although there were issues during the implementation phase, attendance to this continuing education intervention was perceived as a positive contribution to the development of these nurses' competencies. This knowledge informs our understanding of how a competency-based approach can guide the training of health professionals from academia to practice. Further research is planned to document its implementation in other clinical settings and its sustainability in units where participants wish to pursue reflective discussions. 


\section{REFERENCES}

Alleyne, J., Jumaa, M.O., 2007. Building the capacity for evidence-based clinical nursing leadership: The role of executive co-coaching and group clinical supervision for quality patient services. Journal of Nursing Management 15, 230-243.

Anderson, J.R., Reder, L.M., Simon, H.A., 1996. Situated learning and education. Educational Researcher 25, 5-11.

Argyris, C., Schön, D.A., 1974. Theory in practice: Increasing professionnal effectiveness. Jossey-Bass, London.

Atkins, S., Murphy, K., 1993. Reflection: A review of the literature. Journal of Advanced Nursing 18, 1188-1192.

Bailey, M.E., Graham, M.M., 2007. Introducing guided group reflective practice in an Irish palliative care unit. International Journal of Palliative Nursing 13, 555-560.

Bartels, J.E., Bednash, G., 2005. Answering the call for quality nursing care and patient safety: A new model for nursing education. Nursing Administration Quarterly 29, 5-13.

Boud, D., Keogh, R., Walker, D., 1985. Promoting reflection in learning: A model, in: Boud, D., Keogh, R., Walker, D. (Eds.), Reflection: Turning experience into learning, New York, NY, pp. $18-40$.

Brookfield, S., 1990. Using critical incidents to explore learners' assumptions, in: Mezirow, J. (Ed.), Fostering critical reflection in adulthood: A guide to transformative and emancipatory learning. Jossey-Bass Publishers, San Francisco, CA, pp. 177-193.

Cronenwett, L., Sherwood, G., Barnsteiner, J., Disch, J., Johnson, J., Mitchell, P., Sullivan, D.T., Warren, J., 2007. Quality and safety education for nurses. Nursing Outlook 55, 122-131.

Dawber, C., 2013a. Reflective practice groups for nurses: a consultation liaison psychiatry nursing initiative: part 1--The model. International Journal of Mental Health Nursing 22, 135144.

Dawber, C., 2013b. Reflective practice groups for nurses: A consultation liaison psychiatry nursing initiative: Part 2 - the evaluation. International Journal of Mental Health Nursing 22, 241248.

Dube, V., Ducharme, F., 2014. Evaluation of a reflective practice intervention to enhance hospitalized elderly care: A mixed method study. Journal for Nurses in Professional Development 30, 34-41.

Duchscher, J.E., 2009. Transition shock: The initial stage of role adaptation for newly graduated registered nurses. Journal of Advanced Nursing 65, 1103-1113. 
Forneris, S.G., Peden-McAlpine, C., 2007. Evaluation of a reflective learning intervention to improve critical thinking in novice nurses. Journal of AdvancedNnursing 57, 410-421.

Frenk, J., Chen, L., Bhutta, Z.A., Cohen, J., Crisp, N., Evans, T., Fineberg, H., Garcia, P., Ke, Y., Kelley, P., Kistnasamy, B., Meleis, A., Naylor, D., Pablos-Mendez, A., Reddy, S., Scrimshaw, S., Sepulveda, J., Serwadda, D., Zurayk, H., 2010. Health professionals for a new century: Transforming education to strengthen health systems in an interdependent world. Lancet 376, 1923-1958.

Gibbs, G., 1988. Learning by doing: A guide to teaching and learning methods. Further Education Unit, London, UK.

Institute of Medicine, 2011. The future of nursing: Leading change, advancing health. The National Academies Press, Washington, DC.

Johns, C., 1995. Framing learning through reflection within Carper's fundamental ways of knowing in nursing. Journal of Advanced Nursing 22, 226-234.

Kemp, P., Rooks, J., Mess, L., 2009. Work-based learning with staff in an acute care environment: a project review and evaluation. Mental Health Practice 12, 31-35.

Kenny, A., Allenby, A., 2013. Implementing clinical supervision for Australian rural nurses. Nurse Education in Practice 13, 165-169.

Kolb, D.A., 1984. Experiential learning: Experience as the source of learning and development. Prentice-Hall, Englewood Cliffs, NJ.

Lakeman, R., Glasgow, C., 2009. Introducing peer-group clinical supervision: an action research project. International Journal of Mental Health Nursing 18, 204-210.

Lasnier, f., 2000. Réussir la formation par compétences. Guérin, Montréal.

McVey, J., Jones, T., 2012. Assessing the value of facilitated reflective practice groups. Cancer Nursing Practice 11, 32-37.

Morrow, S., 2009. New graduate transitions: Leaving the nest, joining the flight. Journal of Nursing Management 17, 278-287.

National Research Council, 2001. Knowing what students know: The science and design of educational assessment. National Academy Press, Washington, DC.

Olofsson, B., 2005. Opening up: psychiatric nurses' experiences of participating in reflection groups focusing on the use of coercion. Journal of Psychiatric \& Mental Health Nursing 12, 259267.

Page, S., Meerabeau, L., 2000. Achieving change through reflective practice: Closing the loop. Nurse Education Today 20, 365-372. 
Paillé, P., Mucchielli, A., 2012. L'analyse qualitative en sciences humaines et sociales, third ed. Armand Colin, Paris.

Patton, M.Q., 2006. Utilization-focused evaluation, fourth ed. SAGE, California.

Peden-McAlpine, C., Tomlinson, P.S., Forneris, S.G., Genck, G., Meiers, S.J., 2005. Evaluation of a reflective practice intervention to enhance family care. Journal of Advanced Nursing 49, 494-501.

Schön, D.A., 1983. The reflective practitioner: How professionals think in action. Temple Smith, London.

Schön, D.A., 1987. Educating the reflective practitioner: toward a new design for teaching and learning in the professions. Jossey-Bass, San Francisco, CA.

Stanley, H., Simmons, S., 2011. Neonatal nurses' perceptions of a work-based learning approach. Nursing Children \& Young People 23, 20-24.

Tardif, J., 2006. L'évaluation des compétences: Documenter le parcours de développement. Chenelière Éducation, Montréal.

Taylor, B., 2001. Identifying and transforming dysfunctional nurse-nurse relationships through reflective practice and action research. International Journal of Nursing Practice 7, 406-413. 
Table 1. Characteristics of facilitators and attendees of the CEI sessions

\begin{tabular}{lrrrr}
\hline & Hospital A & Hospital B \\
Sessions $(n)$ & & 94 & & 50 \\
Attendees/session $(n)$ & & $1-9$ & & $1-11$ \\
Attendees/session (mean) & Facilitators & Attendees & Facilitators & Attendees \\
\hline & 7 & 26 & 11 & 29 \\
\hline$n$ & $2 / 5$ & $6 / 20$ & $1 / 10$ & $2 / 27$ \\
Gender (M/F) & $28-42$ & $22-41$ & $28-53$ & $21-37$ \\
Age (years) & $3-20$ & 10 months-3 & $8-33$ & 1 month-3 \\
Clinical experience (years) & $1-20$ & $1-13$ & $1-11$ & $1-10$ \\
Sessions animated/attended (n) & 12 & 7 & 4 & 4 \\
Sessions animated/attended (mean) & & & &
\end{tabular}

Table 2. Data collection

\begin{tabular}{|c|c|}
\hline Sample & Data collection technique and content \\
\hline $\begin{array}{l}\text { Nurses with } \\
\text { managing roles } \\
(n=12)\end{array}$ & $\begin{array}{l}\text { Individual journal: } \\
\text { - Perception of the animator's experience } \\
\text { - Feedback given to the animator } \\
\text { Focus groups } \\
\text { - Utility, acceptability and feasibility of the CEI }\end{array}$ \\
\hline $\begin{array}{l}\text { Nurses who } \\
\text { facilitated the } \\
\text { sessions }(n=18)\end{array}$ & $\begin{array}{l}\text { Individual journal: } \\
\text { - Content of each session (timing, attendance, topics, social climate, } \\
\text { what went well, what went wrong, utility of the reflection plan, and } \\
\text { contextual factors that could have influenced the session) } \\
\text { - Self-assessment of animation (strengths, weaknesses, obstacles, } \\
\text { means to improve) }\end{array}$ \\
\hline NGN $(n=55)$ & $\begin{array}{l}\text { Before the CEI } \\
\text { Self-assessment of competencies: } \\
\text { - Self-rated score on cognitive learning models of clinical reasoning } \\
\text { (authors, 2014) and clinical leadership (authors, 2011) } \\
\text { After the CEI } \\
\text { Self-assessment of competencies: } \\
\text { - With comments on their perception of the CEI's contribution to } \\
\text { their development } \\
\text { Individual interviews } \\
\text { - Utility, acceptability and feasibility of the CEI }\end{array}$ \\
\hline $\begin{array}{l}\text { Research assistant } \\
(n=1)\end{array}$ & $\begin{array}{l}\text { Field notes } \\
\text { - During coordination of the CEI in both hospitals }\end{array}$ \\
\hline
\end{tabular}




\section{A calm place on a care unit}

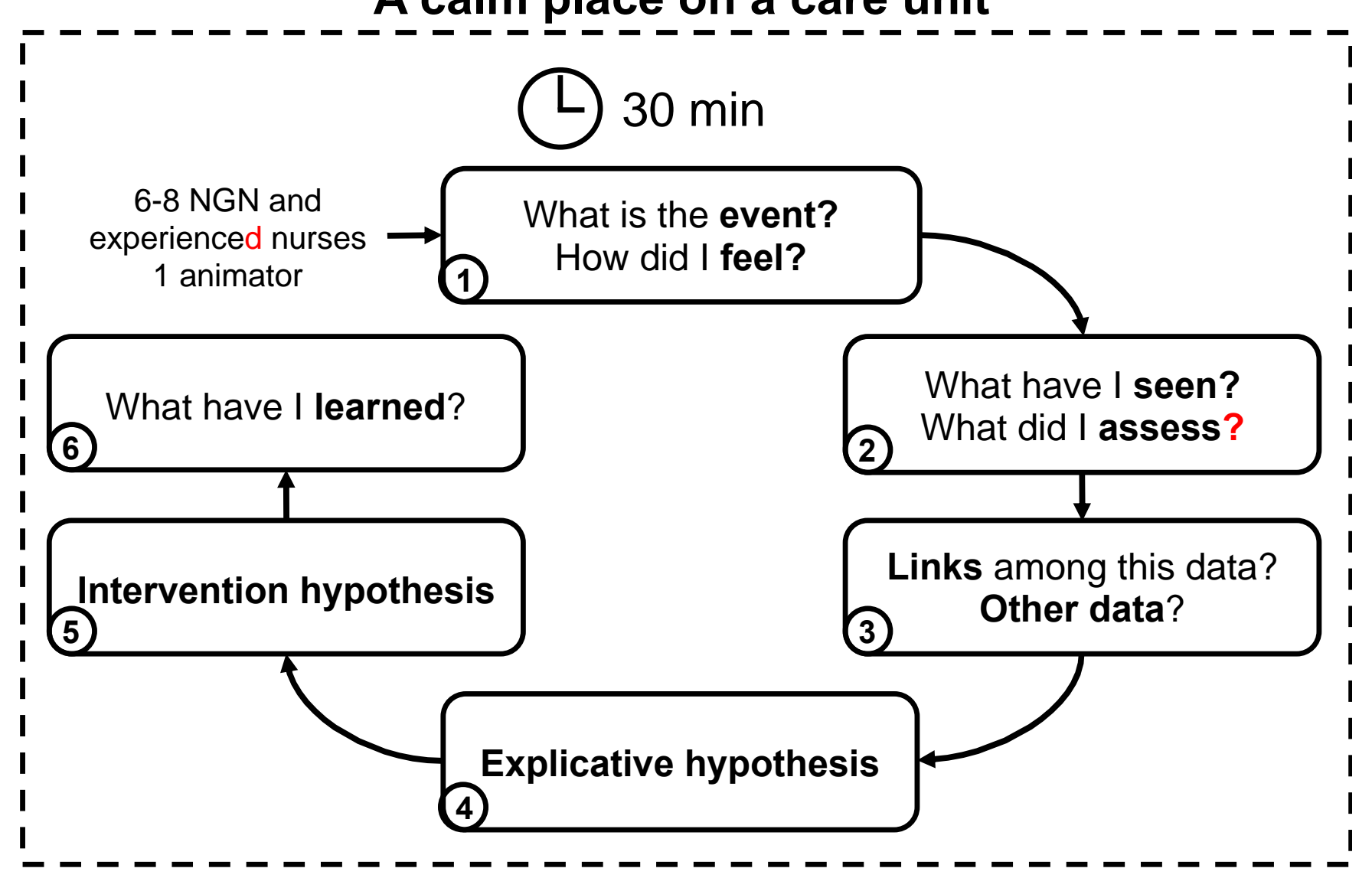

Figure 1. Diagram of the reflective approach 